\title{
Early Prevention of Childhood Obesity: Another Promise or a Reliable Path for Battling Childhood Obesity?
}

\author{
Rüdiger von Kries ${ }^{a} \quad$ Manfred J. Müller ${ }^{b}$ Joachim Heinrich ${ }^{c}$ \\ anstitute of Social Pediatrics and Adolescent Medicine, Ludwig-Maximilians University \\ of Munich, Munich, ${ }^{\mathrm{b}}$ Institute of Human Nutrition and Food Science, Christian-Albrechts \\ University of Kiel, Kiel, 'Institute of Epidemiology I, German Research Center for \\ Environmental Health, Helmholtz Zentrum München, Neuherberg, Germany
}

A recently published article by Gillman and Ludwig [1] strongly advocates for early obesity prevention. Indeed a child's obesity life course appears to be determined by the age of 6 years as shown in compiled data on the natural course of BMI distribution from birth to 14 years (fig. 1) in three German birth cohorts (Kiel Obesity Prevention Study (KOPS) [2], Dortmund Nutritional and Anthropometric Longitudinally Designed (DONALD) Study [3], Multicenter Allergy Study (MAS) [4]) in a collaboration facilitated by the German Adiposity Network (EPI Germany; www.kompetenznetz-adipositas.de/kompetenznetz/konsortien. $h t m l ? L=1)$. The patterns in boys and girls were very similar. Among the obese children with a BMI above the 97 th percentile at 6 years $50.0 \%$ (95\% CI 33.3-66.7\%) remained obese, and 40.0\% (95\% CI 26.7-53.3\%) became overweight (BMI > 90th percentile). Among overweight children with a BMI between the 90 th and 97 th percentile at 6 years $24.2 \%$ (95\% CI $13.6-$ $34.9 \%$ ) stayed overweight until age 14 years, and $27.3 \%$ (95\% CI 16.7-37.9\%) became obese, whereas only $2.1 \%$ (95\% CI 1.6-3.1\%) of the children who had a BMI below the median at the age of 6 years developed obesity at the age of 14 years. Overweight at age 5 was the strongest predictor of being overweight at age 10 years after adjustment for several co-factors, as also demonstrated in another German cohort [5]. Therefore, any effort to avoid an elevated BMI within the first 6 years of life appears to be strongly justified. But is there sufficient evidence for effective preventative action?

Gillman and Ludwig [1] based their argument on evidence from animal studies demonstrating irreversible derangements in offspring's adiposity and metabolism related to adverse pre- and perinatal conditions. Such proof of principle, however, is difficult to translate into effective prevention programs in humans, although the authors suggested that a large 


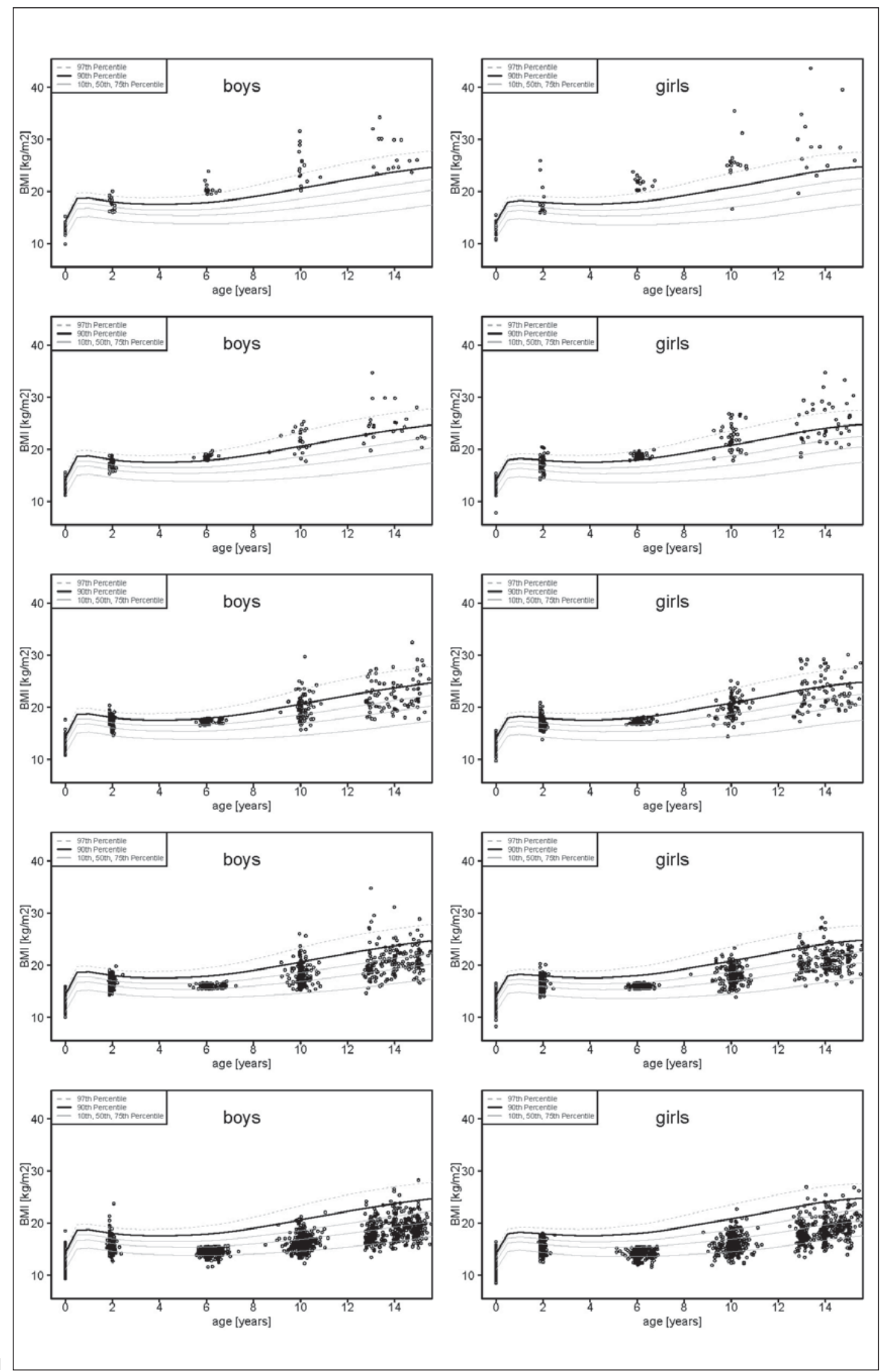

(For Legend see next page.) 
von Kries et al.: Early Prevention of Childhood Obesity: Another Promise or a Reliable Path for Battling Childhood Obesity?

potential to do so exists by avoiding four risk factors identified in the VIVA project. These four risk factors, all of which may be amenable to intervention, include smoking in pregnancy, excessive gestational weight gain, breastfeeding for less than 12 months and sleeping less than $12 \mathrm{~h}$ /day during infancy. While the presence of all four risk factors was associated with an obesity prevalence of $29 \%$, in the absence of all four risk factors the prevalence of obesity was only $6 \%$.

Caution with respect to such a large promise is justified because of the possibility of residual confounding and the limited chances for implementation. An association between smoking in pregnancy and childhood overweight was confirmed in two meta-analyses [6, 7], and an association between nicotine exposure and higher BMI in the offspring has also been confirmed in animal studies [8-10]. However, it was also shown that children exposed to paternal or household smoking in utero or infancy also had an increased risk of being overweight and obese. In mutually adjusted models this risk was similar in magnitude to that of children with intrauterine exposure to maternal smoking [11-14]. Because the intrauterine exposure to nicotine is about fourfold higher in fetuses of smoking mothers as compared to the dose of exposure related to paternal or household smoking [15], substantially larger effect estimates for maternal smoking in pregnancy than for paternal smoking would have been anticipated. Further doubt regarding a causal association arises from sibling studies in which one sibling was exposed to maternal smoking in pregnancy and the other was not [16, 17]. In an analysis stratified by maternal smoking habits across the first and second pregnancies, an increased risk for overweight in young men could only be detected if the mother smoked during both pregnancies. Smoking in either pregnancy only was not associated with overweight in the exposed son. Similar findings were reported by Gilman et al. [16] who assessed the effects of maternal smoking during pregnancy on children's growth and development in 16,619 siblings using conditional likelihood methods. The BMI in offspring of mothers who had been smoking during pregnancy was significantly higher in the unconditional analyses. However, with adjustment for unmeasured family conditions by analyses conditional on family-specific intercepts providing effect estimates free from bias due to potentially confounding factors to which both siblings were exposed, the effects of maternal smoking in pregnancy decreased and were no longer significant. So although there are good reasons to avoid smoking in pregnancy, the presumed effect of avoiding smoking in pregnancy to reduce likelihood of childhood overweight might reflect an artifact in epidemiological research.

Similarly the notion that there is a protective effect from breastfeeding against childhood obesity is not yet definitely proven despite a myriad of observational studies [18]. Pediatricians spend a great deal of office time consulting parents about sleeping problems in infancy. Unfortunately, there are no evidence-based concepts to solve children's sleep problems, and proof for an efficacious population advice to change sleep habits is definitely lacking.

Avoidance of excessive gestational weight gain (GWG) may be a viable option in preventing childhood obesity $[19,20]$. Excessive GWG can be identified early in pregnancy, and reversal of excessive GWG early in pregnancy [21] was found to reverse the risk for overweight in the

Fig. 1. Previous and subsequent course of BMI of boys (left panel) and girls (right panel) at different BMI categories at the age of 6 years. From above to below: First row: Obese boys and girls at the age of 6 years; Second row: Overweight boys and girls at the age of 6 years; Third row: Boys and girls lying between the 90 th and 75th BMI percentile at the age of 6 years; Fourth row: Boys and girls lying between the 75th and 50th BMI percentile at the age of 6 years; Fifth row: Boys and girls lying below the $50^{\text {th }}$ BMI percentile at the age of 6 years. The data were generated by merging three German birth cohort studies (KOPS [2], DONALD [3] and MAS [4]). 
von Kries et al.: Early Prevention of Childhood Obesity: Another Promise or a Reliable Path for Battling Childhood Obesity?

offspring [22]. We are awaiting results from randomized trials on the impact of avoiding excessive GWG on later overweight. These trials require long-term follow-up: As depicted in figure 1, the proportion of children with high or low BMI at the age of 2 among those overweight, obese or with a BMI below the 50th percentile at the age of 6 years was almost identical. As previously shown, this reflects a high remission rate from overweight at the age of 2 years [23, 24]. Even if such long-term effects for avoidance of excessive GWG are confirmed, their potential contribution to a successful strategy for obesity prevention might prove limited. In an analysis of the attributable risk fraction excessive GWG accounted for only $1.9 \%$ of the risk for childhood overweight [14].

Early prevention of childhood obesity: a promise that may prove hard to keep.

\section{References}

$>1$ Cichocki M, Singer G, Beyerlein S, Zeder SL, Schober P, Hollwarth M: A case of necrotizing enterocolitis associated with adenovirus infection in a term infant with 22q11 deletion syndrome. J Pediatr Surg 2008;43:e5-8.

-2 Plachta-Danielzik S, Landsberg B, Seiberl J, Gehrke MI, Gose M, Kehden B, Muller MJ: Longitudinal data of the Kiel Obesity Prevention Study (KOPS) (in German). Bundesgesundheitsbl Gesundheitsforsch Gesundheitsschutz 2012;55:885-891.

-3 Buyken AE, Alexy U, Kersting M, Remer T: The donald cohort. An updated overview on 25 years of research based on the Dortmund Nutritional and Anthropometric Longitudinally Designed Study (in German). Bundesgesundheitsbl Gesundheitsforsch Gesundheitsschutz 2012;55:875-884.

4 Bergmann RL, Bergmann KE, Lau-Schadensdorf S, Luck W, Dannemann A, Bauer CP, Dorsch W, Forster J, Schmidt E, Schulz J, et al: Atopic diseases in infancy. The German Multicenter Atopy Study (MAS-90). Pediatr Allergy Immunol 1994;5:19-25.

5 Pei Z, Flexeder C, Fuertes E, Thiering E, Koletzko B, Cramer C, Berdel D, Lehmann I, Bauer CP, Heinrich J: Early life risk factors of being overweight at 10 years of age: results of the German birth cohorts GINIPLUS and LISAPLUS. Eur J Clin Nutr 2013;67:855-862.

6 Ino T: Maternal smoking during pregnancy and offspring obesity: meta-analysis. Pediatr Int 2010;52:94-99.

7 Oken E, Levitan EB, Gillman MW: Maternal smoking during pregnancy and child overweight: systematic review and meta-analysis. Int J Obes (Lond) 2008;32:201-210.

-8 Gao YJ, Holloway AC, Zeng ZH, Lim GE, Petrik JJ, Foster WG, Lee RM: Prenatal exposure to nicotine causes postnatal obesity and altered perivascular adipose tissue function. Obes Res 2005;13:687-692.

-9 Oliveira E, Moura EG, Santos-Silva AP, Fagundes AT, Rios AS, Abreu-Villaca Y, Nogueira Neto JF, Passos MC, Lisboa PC: Short- and long-term effects of maternal nicotine exposure during lactation on body adiposity, lipid profile, and thyroid function of rat offspring. J Endocrinol 2009;202:397-405.

10 Somm E, Schwitzgebel VM, Vauthay DM, Camm EJ, Chen CY, Giacobino JP, Sizonenko SV, Aubert ML, Huppi PS: Prenatal nicotine exposure alters early pancreatic islet and adipose tissue development with consequences on the control of body weight and glucose metabolism later in life. Endocrinology 2008;149:6289-6299.

-11 Harris HR, Willett WC, Michels KB: Parental smoking during pregnancy and risk of overweight and obesity in the daughter. Int J Obes (Lond) 2013;37:1356-1363.

12 Kleiser C, Schaffrath Rosario A, Mensink GB, Prinz-Langenohl R, Kurth BM: Potential determinants of obesity among children and adolescents in Germany: results from the cross-sectional KIGGS study. BMC public health 2009;9:46.

13 Pirkola J, Pouta A, Bloigu A, Hartikainen A-L, Laitinen J, Jarvelin M-R, Vaarasmaki M: Risks of overweight and abdominal obesity at age 16 years associated with prenatal exposures to maternal prepregnancy overweight and gestational diabetes mellitus. Diabetes Care 2010;33:1115-1121.

14 Plachta-Danielzik S, Kehden B, Landsberg B, Schaffrath Rosario A, Kurth BM, Arnold C, Graf C, Hense S, Ahrens W, Muller MJ: Attributable risks for childhood overweight: evidence for limited effectiveness of prevention. Pediatrics 2012;130:e865-871.

15 Chan D, Klein J, Koren G: Objective assessment of environmental tobacco smoke (ETS) exposure in pregnancy and childhood; in Witten M, Watson RR (eds): Environmental Tobacco Smoke. London, Informa Healthcare, 2000, pp 319-335.

16 Gilman SE, Gardener H, Buka SL: Maternal smoking during pregnancy and children's cognitive and physical development: a causal risk factor? Am J Epidemiol 2008;168:522-531.

$\checkmark 17$ Iliadou AN, Koupil I, Villamor E, Altman D, Hultman C, Langstrom N, Cnattingius S: Familial factors confound the association between maternal smoking during pregnancy and young adult offspring overweight. Int J Epidemiol 2010;39:1193-1202.

18 Beyerlein A, von Kries R: Breastfeeding and body composition in children: will there ever be conclusive empirical evidence for a protective effect against overweight? Am J Clin Nutr 2011;94(suppl):1772S-1775S. 
19 Streuling I, Beyerlein A, von Kries R: Can gestational weight gain be modified by increasing physical activity and diet counseling? a meta-analysis of interventional trials. Am J Clin Nutr 2010;92:678-687.

20 Plachta-Danielzik S, Bartel C, Raspe H, Thyen U, Landsberg B, Muller MJ: Assessment of representativity of a study population - experience of the Kiel Obesity Prevention Study (KOPS). Obes Facts 2008;1:325-330.

-21 Karaolis-Danckert N, Buyken AE, Sonntag A, Kroke A: Birth and early life influences on the timing of puberty onset: results from the DONALD (Dortmund Nutritional and Anthropometric Longitudinally Designed) study. Am J Clin Nutr 2009;90:1559-1565.

22 Degen GH, Blaszkewicz M, Shi L, Buyken AE, Remer T: Urinary isoflavone phytoestrogens in German children and adolescents - a longitudinal examination in the DONALD cohort. Mol Nutr Food Res 2011;55:359-367.

23 von Kries R, Reulen H, Bayer O, Riedel C, Diethelm K, Buyken AE: Increase in prevalence of adiposity between the ages of 7 and 11 years reflects lower remission rates during this period. Pediatr Obes 2013;8:13-20.

24 von Kries R, Beyerlein A, Muller MJ, Heinrich J, Landsberg B, Bolte G, Chmitorz A, Plachta-Danielzik S: Different age-specific incidence and remission rates in pre-school and primary school suggest need for targeted obesity prevention in childhood. Int J Obes (Lond) 2012;36:505-510. 